DOI 10.37882/2500-3682.2021.02.10

\title{
МОДЕЛИРОВАНИЕ СОЦИАЛЬНОЙ БЕЗОПАСНОСТИ РЕГИОНА В КОНТЕКСТЕ СОЦИАЛЬНО-ФИЛОСОФСКОГО И РЕГИОНАЛИСТСКОГО ДИСКУРСОВ
}

\section{MODELING OF THE SOCIAL SAFETY OF THE REGION IN THE CONTEXT OF SOCIO-PHILOSOPHICAL AND REGIONALIST DISCOURSES}

S. Kononov

Summary: The article is devoted to the development of a model of social security in the region, representing a comprehensive vision of various aspects of interaction between man and society on the way to preserve social security. The aim of the study is an attempt to synthesize the provisions of various scientific and socio-philosophical concepts of social security with the provisions of regional studies into a single systemic model of social security in the region. The implementation of this goal is carried out by the author using a methodology based on a civilizational approach, which asserts the uniqueness of each of the regions, a systematic approach that reveals the social system of a region as a multi-core phenomenon in which various social levels are distinguished; a structuralist approach, which proves that social conditions for safe life depend on the development and organization of the social environment; semiotic approach aimed at analyzing the region as a spatial, locally distinguished social system formed around a complex of regional values; an instrumental approach that pays attention to the impact of mechanisms leading to the mobilization of regional interests. The novelty of the presented research is associated with the development of a model of social security of the region based on the principle of complementarity of philosophical concepts of social security and the provisions of regional studies. The result of the study is a statement of the impossibility of covering this phenomenon in models developed in individual sciences that form scattered images of the social security of the region, but do not cover the entirety of this phenomenon. The second result of the study is the formation of a model of social security of the region, which allows taking into account civilizational, systemic, structural, value, instrumentally constructed parameters. The third result is proof of the possibility of building a social security system based on values, the mobilization of which takes place within the framework of a dialogue between external and intra-regional social discourses.

Keywords: social security model, social security, security concepts, civilizational approach, systems approach, structuralist approach, social system of the region, life safety, social environment, regional interests.

\section{Ввецение}

A ктуальность исследований социальной безопасности регионов связана с совершившимся в последние десятилетия усилением внимания соци-
Кононов Сергей Викторович

К.ф.н., Забайкальский государственный университет kononov7744@yandex.ru

Аннотация: Статья посвящена разработке модели социальной безопасности региона, представляющей комплексное видение разнообразных аспектов взаимодействия человека и общества на пути сохранения социальной безопасности. Целью исследования является попытка синтеза положений различных научных и социально-философских концепций социальной безопасности с положениями регионалистики в единую системную модель социальной безопасности региона. Реализация данной цели проводится автором с использованием методологии, основанной на цивилизационном подходе, утверждающем уникальность каждого из регионов, системном подходе, раскрывающим социальную систему региона в качестве многоосновного феномена, в котором выделяются различные социальные уровни; структуралистском подходе, доказывающем, что социальные условия безопасной жизнедеятельности зависят от развитости и организации социальной среды обитания; семиотическом подходе, направленном на анализ региона, как пространственной, локально выделенной социальной системы, сформированной вокруг комплекса региональных ценностей; инструменталистского подходе, обращающем внимание на влияние механизмов, ведущих к мобилизации региональных интересов. Новизна представленного исследования связывается с разработкой модели социальной безопасности региона на основании принципа дополнительности философских концепций социальной безопасности и положений регионалистики. Результатом исследования является констатация невозможности охвата данного явления в моделях, разрабатываемых в отдельных науках, формирующих разрозненные образы социальной безопасности региона, но не охватывают всей полноты данного явления. Вторым результатом исследования является формирование модели социальной безопасности региона, позволяющей учитывать цивилизационные, системные, структурные, ценностные, инструментально конструируемые параметры. Третьим результатом является доказательство возможности построения системы социальной безопасности на основе ценностей, мобилизация которых проходит в рамках диалога между внешнимии внутри- региональными социальными дискурсами.

Ключевые слова: модель социальной безопасности, социальная безопасность, концепции безопасности, цивилизационный подход, системный подход, структуралистский подход, социальная система региона, безопасность жизнедеятельности, социальная среда, региональные интересы.

альных наук к проблемам, связанным с обеспечением высокого уровня жизнедеятельности людей, проживающих в разных региональных: условиях. При этом исследования социальной безопасности на уровне регионов, ведутся преимущественно в работах с использованием 
государственно-правового, представленного в трудах Р.Г. Яновского, Г.В. Атаманчука, Т.А. Заславской, Н.Н. Потрубача; социологического, представленного в трудах Ю.А. Левады, В.В. Зыкова, В.Н. Кузнецова, Л.Д. Гудкова; психолого-педагогического, представленного в трудах И.А. Баевой, В.А. Соснина, А.А. Дронова, З.В. Масаевой; экономического подхода, представленного в трудах Л.И. Абалкина, И.Я. Богданова, С.Ю. Глазьева, экологического, представленного в трудах В.Н. Турченко, военного подхода, представленного в трудах И.С. Даниленко, С.Л. Никонович, В.И. Лутовинова. Однако исследования, проводимые в рамках данных подходов, раскрывают отдельные характеристики социальной безопасности региона, но не охватывают всей полноты данного явления. Это говорит о его сложности и многогранности, а также, указывает на необходимость синтеза имеющегося знания по различным аспектам социальной безопасности регионов. На наш взгляд, эту проблему можно решить в рамках сочетания положений философских концепций социальной безопасности с положениями регионалистики, представленной трудами А.В. Возженикова, В.В. Стрельченко, Н.П. Медведева, В.К. Левашова [8, с. 32], с помощью чего возможно осмысление разнообразных аспектов взаимодействия человека и общества на пути сохранения социальной безопасности регионов.

\section{Степень исследованности}

Философия имеет значительный и неоднозначный запас достижений в сфере моделирования социальной безопасности, куда входят различные модели, предлагавшиеся В произведениях Платона, Аристотеля, А. Аврелия, Ф. Аквинского, Т. Гоббса, Б. Спинозы, Дж. Локка, Ж.-Ж. Руссо, И. Канта, Г. Гегеля, К. Маркса [10], посвященных сущности и функциям государственных и социальных образований. Исторически модель социальной безопасности, разрабатываемая в рамках европоцентристского подхода, аспекты которого формировались положениями философии О. Конта, М. Вебера, Р. Киплинга, Э. Трельча, Ф. Фукуямы, Г. Моргентау, 3. Бжезинского, Г Киссинджера [20], которые основывались на утверждении единственного и однонаправленного пути развития общества, нацеленного на идеалы солидарности, и обеспечивающего его членам защиту от социальных угроз. Основу моделирования социальной безопасности на основе европоцентристского подхода представляет концепция, которая предполагает распространение норм глобальной безопасности, ориентируясь на политику подавления региональных традиций управления и представлений о власти. Этой модели может быть противопоставлена модель, предлагаемая цивилизационным подходом, основы которого были заложены Н.Я. Данилевским, О. Шпенглером, Н.С. Трубецким, А. Тойнби, А. Петерсом, О. Сулеймановым, Э. Саидом, С. Хантингтоном [14], представляющих видение мира, строящегося на основе развития мирного сотрудниче- ства государств, народов, регионов. Однако разработка модели безопасности регионов в рамках цивилизационного подхода нуждается в привлечении дополнительных теоретических подходов и методов, которые позволили бы структурно выделить и определить сущность и функционал данного явления.

Целью исследования является попытка синтеза положений различных научных и социально-философских концепций социальной безопасности с положениями регионалистики в единую системную модель социальной безопасности региона.

Существенное значение для моделирования социальной безопасности региона имеет методология, основанная на положениях цивилизационного подхода, суть которого состоит в признании равноправия различных регионов вне зависимости от уровня их развития, сложности и самобытности. Использование системного подхода раскрывает социальную структуру региона как сложный и многоосновный феномен, в котором выделяются различные уровни материальной, духовной, художественной, народной, традиционной, инновационной культуры. Структуралистский подход анализирует становление социальных систем безопасности региона, в связи с различными уровнями социальной деятельности, продиктованными интересами региональных групп. Семиотический подход направлен на анализ региона, территорию социальной субъектности, объединенную вокруг комплекса ценностей и интересов. Инструменталистский подход исследует влияние механизмов, используемых в случае мобилизации региональных интересов. Новизна исследования обусловлена формированием исследовательской модели социальной безопасности региона, основанной на принципах дополнительности цивилизационного, системного, структурного, инструменталистского подходов к формированию модели социальной безопасности региона.

\section{Результаты исследования}

Исследования проблем социальной безопасности на уровне регионов, а также моделирование условий, способствующих их предотвращению, ведутся с использованием государственно-правового, социологического, психологического, экономического, экологического, военного подходов, которые, формирующие разрозненные образы социальной безопасности региона, но не охватывающие всей полноты данного явления. Возможность синтеза имеющегося знания по различным аспектам социальной безопасности регионов представляет использование философских подходов, позволяющих на основании принципа дополнительности сформировать исследовательскую модель, позволяющую учитывать различные параметры данного явления. В рамках философии разработано множество альтернативных 
концепций безопасности, включая европоцентристские, основанные на вере в необходимость подавления региональных традиций управления и безопасности и цивилизационные, основанные на вере в возможность построения мира, на основе коллаборации всех государств, народов, регионов. Согласно цивилизационным концепциям, понятие о социальной безопасности носит релятивный и субъективный характер, оценка которого зависит от ценностей, доминирующих в каждом из региональных сообществ, которые, с одной стороны стремятся к сохранению своего ценностного ядра, с другой - к саморазвитию, а, следовательно, к изменениям в условиях постоянно изменяющегося мира. Системный подход к исследованию данной проблемы показывает, что каждая региональная подсистема социальной безопасности формируется в контексте системы общественной коллаборации регионального сообщества с окружающим миром. Вместе с этим большое значение имеет субъективная составляющая явления социальной безопасности региона, которая включает социальные представления о том, что есть социальная защищенность. Поэтому существенное значение для моделирования социальной безопасности региона имеет категория «жизненного мира», которая синтетически рисует место расположения региона, его одновременной закрепленности в физическом и социальном мире, а также в психологическом и информационном пространстве. Согласно этому подходу, социальная безопасность региона, будучи подсистемой общества, подразделяется на две подсистемы, одной из которых является объективная защищенность от социальных угроз, другой - субъективная защищенность от страха в отношении социальных угроз.

Структурный анализ показывает, что, во-первых, в рамках этой модели, в качестве факторов формирования социальной безопасности региона выступают, конкретные природные, исторические и социальные условия, с которыми человек и региональное сообщество вступают в экзистенциальные отношения. Во-вторых, фактором, становления социальной безопасности региона здесь признаются региональные ценности, сформированные в рамках региональных представлений о защищенности от социальных проблем, часто несопоставимых с системами других народов. В-третьих, моделирование системы социальной безопасности включает в себя представление реальных универсальных и региональных угроз, которые могут изменить региональные системы ценностей, интересы и представления, а также анализ и проектирование форм защиты интересов регионального сообщества, за которые готовы бороться члены регионального сообщества. В-четвертых, модель социальной безопасности региона предполагает проведение анализа формирования региональных интересов и ценностей, конструирование и мобилизация которых проходит в рамках противостояния, взаимодействия и диалога между внешними по отношению к региону и внутри региональным дискурсом.

\section{ОбсужАение результатов}

\section{Аспекты безопасности в коншепциях шивилизашионного по $\triangle$ хо $а$}

С точки зрения цивилизационного подхода социальное развитие не может совершаться линейно и однонаправлено, а имеет нелинейный и циклический характер, который зависит от особенностей каждого из конкретно-исторических регионов, на которые подразделяется окружающий мир. Угрозу социальной безопасности, с этой точки зрения, представляет совершившийся в западных цивилизациях переход от ценностно-ориентированного к технократическому рационализму, который стал причиной бездуховности и поведенческого иррационализма человечества. При этом, как пишет, М. Херсковиц определение того, что нормально и что ненормально, зависит только от организации социальных отношений в рамках каждого из регионов [18].

Из чего можно сделать вывод о том, что в основе моделирования социальной безопасности региона должен находиться анализ социальных условий жизнедеятельности, которые зависят от особенностей среды обитания. Понятийный фундамент здесь представляет термин «региональный социум», понимаемый как отражение состояния общественного бытия на уровне региона. Эти идеи развиваются в трудах Э. Гуссерля, М. Хайдеггера, А. Шюца, Д. Горовица, Р. Дарендорфа, Д. Елазара, М. Джонса [19], которые считают, что моделью социального пространства является образ общества, как «жизненного мира», в котором протекает социальная деятельность человека. Пространственное измерение региона рассматривается ими, как взаимоотношение региональных сообществ и социальных институтов, соотнесенных с пространством, территорией, местом.

\section{Аспекты безопасности в коншепшиях регионалистики}

«Жизненный мир» региона характеризуется особыми природно-ландшафтными условиями, которые формируют у близко-проживающих народов общие способы хозяйствования, формы религиозного и нравственного мировоззрения, схожие экзистенциальные ценности, правовые и политические структуры, объединяющие их в единое целое. Однако системное представление о сущностном строении и единстве региональной среды раскрывается через соотнесение антиномичных понятий о регионе, как явлении. С одной стороны, структура региона может пониматься в качестве субнациональной единицы, находящейся в рамках более крупного федерального образования. В этом качестве регион рассматривается в трудах представителей регионали- 
стики, таких, как В. Изард, Н.П. Медведев, Р.Ф. Туровский, С. Кара-Мурза, Л.Н. Захарова [4, с. 34], которые понимают «регион» как специфическое социальное образование, вписанное в общий «пейзаж», представленный однородной физической и социальной средой.

\section{Аспекты безопасности в коншепциях системного по $\triangle$ хо $\Delta$ a}

С другой точки зрения, регион может рассматриваться, как структура, включающая обширную территорию, куда входит несколько стран, объединяемых по признаку географической или социальной близости. Эта концепция применяется в исследованиях О. Шпенглера, А. Тойнби, Ф. Ратцеля, Х. Дж. Маккиндера, Л. Фробениуса, Р. Челлена [15], которые обратили внимание на тему межрегионального взаимодействия, что позволило проводить анализ распространения социальных изменений, влияющих на безопасность регионов. Модель этой социальной системы в социальной философии представляют в образе структуры, состоящей из подсистем, в состав которых входит социальная безопасность региона. Эта структура, как показывает А.И. Сухарев, В.В. Маркин, С.В. Полутин [12], состоит из ряда тесно взаимосвязанных и иерархических уровней.

Моделирование социальной безопасности как общественной подсистемы, показывает, что, входя в систему общества, как особый элемент, она в свою очередь подразделяется на две особые сферы безопасности, одной из которых является защищенность от социальных угроз, включая угрозу нужды и бедности, другой - защищенность от страха в отношении социальных угроз. Среди них, с одной стороны, выделяется такая сфера безопасности, как защищенность от реальных социальных угроз, которая зависит от объективных факторов, выступающих в качестве характеристик социальной структуры региона. Соответственно, каждая региональная система социальной безопасности формируется в контексте системы объективных связей человека с окружающим миром, что подтверждают исследования О. Больнова, И. Дерболава, Э. Гидденса, О.А. Кармадонова [6].

\section{Аспекты безопасности в структуралистских коншепциях}

Однако ряд исследователей, указывают на субъективную составляющую явления социальной безопасности региона, которое представляется им зависимым от сочетания различных социальных институтов и групп, оказывающих влияние на региональные представления о том, что есть социальная безопасность. Они отмечают, что социальное пространство региона представляет собой необходимое условие и особую форму существования регионального сообщества, как субъекта соци- ального действия. В частности, Р.Г. Яновский считает, что социальная безопасность представляет состояние защищенности некой общности людей, которая характеризуется общностью социальной деятельности и региональных ценностей. Ценности, которые, как пишет B.М. Капицын, объединяют региональное пространство в единую социальную структуру, центром которой является региональный интерес, являющийся ведущим регионообразующим фактором [5, с. 115].

Эта идея играет ключевую роль в организации регионального пространства, придавая ему единство и системность, влияющие на становление социальной безопасности субъектов этого пространства. Она представляется в качестве автономной общественной подсистемы, функцией которой является защита «жизненно важных целей, идеалов, ценностей, интересов социальных субъектов макро- и микроуровней, сохранения и развития человеческого потенциала, поддержания эффективности стимулирования деятельности людей, систем их социализации и жизнеобеспечения, поддержание нравственности» [4, с. 36].

Из этого можно сделать вывод о том, что социальная безопасность регионов формируется под влиянием политических, экономических и социальных институтов вокруг региональных ценностей и интересов [13, с. 90]. Предметом исследований социальной безопасности с учетом этой модели, является выявление социальных интересов региональных групп, определение их проводников, разработка методов и инструментов их распространения, а также обоснование значимости их применения. Ведущим фактором становления социальной безопасности региона здесь представляется восприятие социально-значимой информации [11].

\section{Безопасность в инструменталистских коншепчиях}

В связи с этим значимо, что в рамках представляемой модели рассматривается не столько структура социальной безопасности, сколько актуальная проблематика взаимодействия региональных социальных систем между собой и с глобализирующимся сообществом. В рамках этой проблематики в одних случаях региональный социум, уверенно сохраняет свою жизнеспособность и самобытность, в других - испытывает доминирующее внешнее воздействие, осуществляемое посредством таких факторов, как идеология, образование, наука и техника. Здесь как, отмечают исследователи проблемы социальной безопасности региона, имеется сложность, заключающаяся в том, что определение безопасности является двусторонним процессом, включающим онтологическую составляющую, благодаря которой субъект обретает безопасное состояние, и гносеологическую составляющую, благодаря которой субъект осознает свое состояние, как безопасное [9]. 
Эта сторона информационного взаимодействия в социальном пространстве региона раскрывается положениями инструменталистского подхода, обращающего внимание на влияние механизмов, осознаваемых в случае развития и мобилизации региональных интересов. В рамках этой методологии анализ региональных систем социальной безопасности требует проведения концептуализации, связанной с процедурами конструирования как инструментами, формирующими образы регионов и региональных проблем безопасности в качестве результата творческой деятельности различных субъектов информационного давления, которые либо «сверху», либо «снизу» инициируют процессы защиты региональных интересов.

Инструменталистские концепции доказывают, что социум влияет на человека, а человек на социум посредством диалога, принципы которого раскрыты М. Бубером, М. Бахтиным, В. Библером [2] через систему знаний, традиций, ценностей. Теоретические разработки этих авторов акцентируют внимание на том, вступая во взаимодействие с окружающим социальным пространством, каждая подсистема общества, включая подсистему социальной безопасности региона, не только изменяется сама, но меняет это пространство в целом. Механизм этого влияния раскрывается в контексте конструктивистских идей О. Вьювера и Б. Бузана [16], выражающим мнение о том, что социальная безопасность региона трансформируется со стороны социальных субъектов, которые создают и распространяют нормы, влияющие на социальную структуру общества. В рамках этой концепции возможно определить структуру социальной безопасности региона, как инструмент, направленный на осознание интересов и ценностей различных региональных групп, от индивида до общества и государства. Ведущими акторами в социальном пространстве региона в контексте этой концепции, признаются социальные институты, которые представляют организационный центр или ядро, оказывающие влияние на складывание систем ценностей, виды деятельности, пассионарных лидеров, в пространстве периферии или сфер влияния [3]. В частности, проводниками региональных интересов могут быть признаны группы элиты, обладающие инструментами социальной мобилизации и оказывающие влияние, как системообразующие региональные ценности, так и на усилия, направленные на их обеспечение. Напротив, проводниками внерегиональных ценностей и интересов на уровне региона признается влияние массовой культуры. Однако важно, что в современной социальной философии, представленной трудами А. Ачарья, Д. Лейка, Дж. Ньюмана [21], признается, что состояние социальной безопасности регионов не может только конструироваться, так как оно имеет объективные параметры своей структуры и реальные проблемы и тенденции развития. Поэтому современная модель социальной безопасности регионов, элемента которой содержатся в описаниях В. Кое, К. Кузака, Ц. Фоусета [17], строится на методологии структурного реализма, учитывающего положения инструменталистских и конструктивистских концепций, так и положения цивилизационного и системного подходов, в которых отражались актуальные проблемы современности и угрозы выживанию региональных сообществ.

\section{Авторская модель сошиальной безопасности регионов}

Учитывая опыт этих исследований, мы считаем необходимым обоснование создания многомерной модели социальной безопасности регионов, которая отражает, как реальный, так и конвенциональный характер данного явления и в качестве наиболее значимого фактора становления социальной безопасности региона признает его социальное пространство, где протекает диалог между региональными социальными группами [6]. В контексте данной концепции становление социальной безопасности региона можно понимать, как процесс, существенную роль в котором играет социальное взаимодействие, в результате чего возникают условия, характеризующейся формированием самооценки регионального сообщества в отношении условий своего существования. Предлагаемая методика разрабатывает видение социального пространства региона, как единства, в котором объединены социальная, коммуникативная и функциональная сферы, влияющие на восприятие и оценку «жизненного мира» в рамках социального сознания региона. В этой модели социальное пространство региона представляется в образе реальной и информационной сферы, в рамках которой формируется порядок социального взаимодействия [6].

В рамках этой модели, в качестве факторов формирования социальной безопасности региона выступают, во-первых, конкретные природные, исторические и социальные условия, понимаемые в качестве «жизненного мира», с которым человек и региональное сообщество вступают в экзистенциальные отношения. В свою структуру региональный социум как система, включает материальный, духовный, художественный, этнический, традиционный, инновационный структурные уровни. Эти уровни составляют содержание пространственной сферы социальной безопасности региона, в которой фиксируется наличие совокупности институциональных и неинституциональных форм, создающих, хранящих, распространяющих региональные интересы и ценности [7, с. 37]. Однако наибольшее влияние на формирование и становление социальной безопасности региона, согласно представленной модели, оказывают нормы и ценностные представления, которые распространяются в обществе посредством воспитания и воздействия окружающей среды, то есть социума, являющегося основой «жизненного мира» и дающего оценку степени сво- 
ей защищенности [1].

Таким образом, в фокусе разрабатываемой здесь модели явления «социальная безопасность региона» находится конструирование многоаспектной модели регионального развития, отражающей процесс развития регионального сообщества, стремящегося к состоянию защищенности от социальных проблем. Процесс моделирования социальной безопасности включает в себя представление реальных универсальных и региональных угрозах, которые могут изменить региональные системы ценностей, интересы и представления, а также анализ и проектирование форм защиты интересов регионального сообщества, за которые готовы бороться члены регионального сообщества. Одновременно с этим модель социальной безопасности региона предполагает проведение анализа формирования региональных интересов, конструирование и мобилизация которых проходит в рамках взаимодействия дискурсов, представляемых властным, то есть политико-административным и региональным, то есть выражающим точку зрения социальных групп, подходами.

В целом модель социальной безопасности региона представляет попытку отразить процесс становления социальной безопасности регионов, испытывающих влияние нормативных и ценностных представлений, прививаемых региональному сообществу посредством воздействия окружающего его социума. Поэтому, с одной стороны, существенное значение для конструирования модели социальной безопасности региона имеет анализ объективных внешних воздействий, представленных глобализационным, государственным, зарубеж- ным влиянием, стремящимся к включению социального пространства региона в свои ареалы. С другой стороны, модель предполагает учет влияния, которое оказывает каждый регион, противопоставляющий внешнему воздействию свою систему интересов и ценностей, которая, обладает своим потенциалом, сформированным историческими, природно-географическими условиями, регулирующими отношения природы, человека, общества и мира, придающим ему единство и системность.

\section{Выво}

Модель социальной безопасности региона представляет образ становления процесса безопасной жизнедеятельности региональных сообществ, испытывающих влияние объективных внешних воздействий, представленных глобализационным, государственным, зарубежным влиянием, стремящимся к включению социального пространства региона в свои ареалы. С другой стороны, модель предполагает учет влияния, которое оказывает каждый регион, противопоставляющий внешнему воздействию свою систему интересов и ценностей, которая, обладает своим потенциалом, сформированным историческими, природно-географическими условиями, регулирующими отношения природы, человека, общества и мира, придающим ему единство и системность. Взаимодействие указанных тенденций в рамках предлагаемой модели является источником непрерывного конструирования нормативных и ценностных представлений, прививаемых региональному сообществу посредством воздействия окружающего его социума, а также социальных договоренностей, направленных на достижение конъюнкции в рамках регионального социума.

\section{ЛИТЕРАТУРА}

1. Ассман Ян. Культурная память. Письмо, память о прошлом и политическая идентичность в высоких культурах древности. М.: Языки славянской культуpы, 2004.368 c. С. 11.

2. Библер В.С. От наукоучения - к логике культуры. Два философских введения в двадцать первый век: монография. М.: Политиздат, 1991. 413 с.

3. Губанов В.М., Сатывалдиева Б. Социальная безопасность как социально-исторический феномен // Молодой ученый. 2015. № 15. С. 577-581.

4. Захарова Л.Н. Региональная культура, как объект исследования // Феномены культуры: сб. ст. 2019. С. 34-38

5. Капицын В.М. Символы национальной идентичности как ресурс soft power // ДИСКУРС-ПИ (Институт философии и права Ур0 РАН, Екатеринбург). 2014. T. 11. № 1. С. 113-118

6. Кармадонов О.А., Ковригина Г.Д. Социальная коньюнкция в ресурсном аспекте // Вестник института социологии. 2016. С. 13-26.

7. К Клюева Е.А. Культурное пространство как научная категория // Общество. Среда. Развитие. 2015. № 4. С. 43-46.

8. Левашов В.К. Социальное государство: исторический генезис и динамика становления в России // Социологические исследования. 2017. № 7. С. 32-46.

9. Литвинов Э.П. Безопасность как философская категория // Электронное научное издание Альманах Пространство и время. 2014. Т. 7. № 1. С. 2.

10. Маркс К. Экономическо-философские рукописи 1844 г. // Маркс К. Энгельс Ф. Соч. М. : Изд. Полит. лит., 1974. Т. 42. С. 41-174.

11. Михайленко А.Н., Скалдуцкий С.В. «Мягкое право» в российско-украинских отношениях // Власть истории и история власти. 2017. Т. 3. № 4 (10). С. $491-515$.

12. Полутин С.В. Объектно-предметное поле социологии региона и регионологии // Развитие социального пространства России: новые вызовы и перспективы. 2018. С. 47-51.

13. Степин В.С. Глобальная культура: многообразие опытов и универсальные ценности // Диалог культур и партнерство цивилизаций: становление глобальной культуры. СПб.: СПбГУП, 2010. Т. 2. С. 71- 92.

14. Хантингтон С. Столкновение цивилизаций. М.: АСТ, 2016.640 c.

15. Челлен Р. Государство как форма жизни. М.: РОССПЭН, 2008. 319 с. 
16. Buzan B., Wæver 0. Regions and Powers. Cambridge: Cambridge University Press, 2003. 564 p.

17. Fawcett L. Regionalism by Emulation: Considerations across Time and Space // Interregionalism and the European Union. Post-revisionist Approach to Europe's Place in a Changing World. Abington: Routledge, 2016. Pp. 33-55.

18. Horowitz D. L. Democracy in Divided Societies // Journal of Democracy. 1993. 4(4). Pp. 18-38.

19. Jones M., Jones R., Woods M. An introduction to political geography: Space, place and politics. N.Y.: Routledge, 2004. 202 p.

20. Kissinger H. World Order. NY: Penguin books, 2015. $420 \mathrm{p}$.

21. Nyman J. What is the value of security? Contextualising the negative/positive debate. Review of International Studies. 2016. 42 (5). Pp. 521-839.

22. Zhukov A., Bernyikevich T. Religious security of the Russian Federation as Reflection object of the philosophy and religious studies // MATEC Web of Conferences. electronic edition. 2018. C. 10003.

(c) Кононов Сергей Викторович (kononov7744@yandex.ru).

Журнал «Современная наука: актуальные проблемы теории и практики»
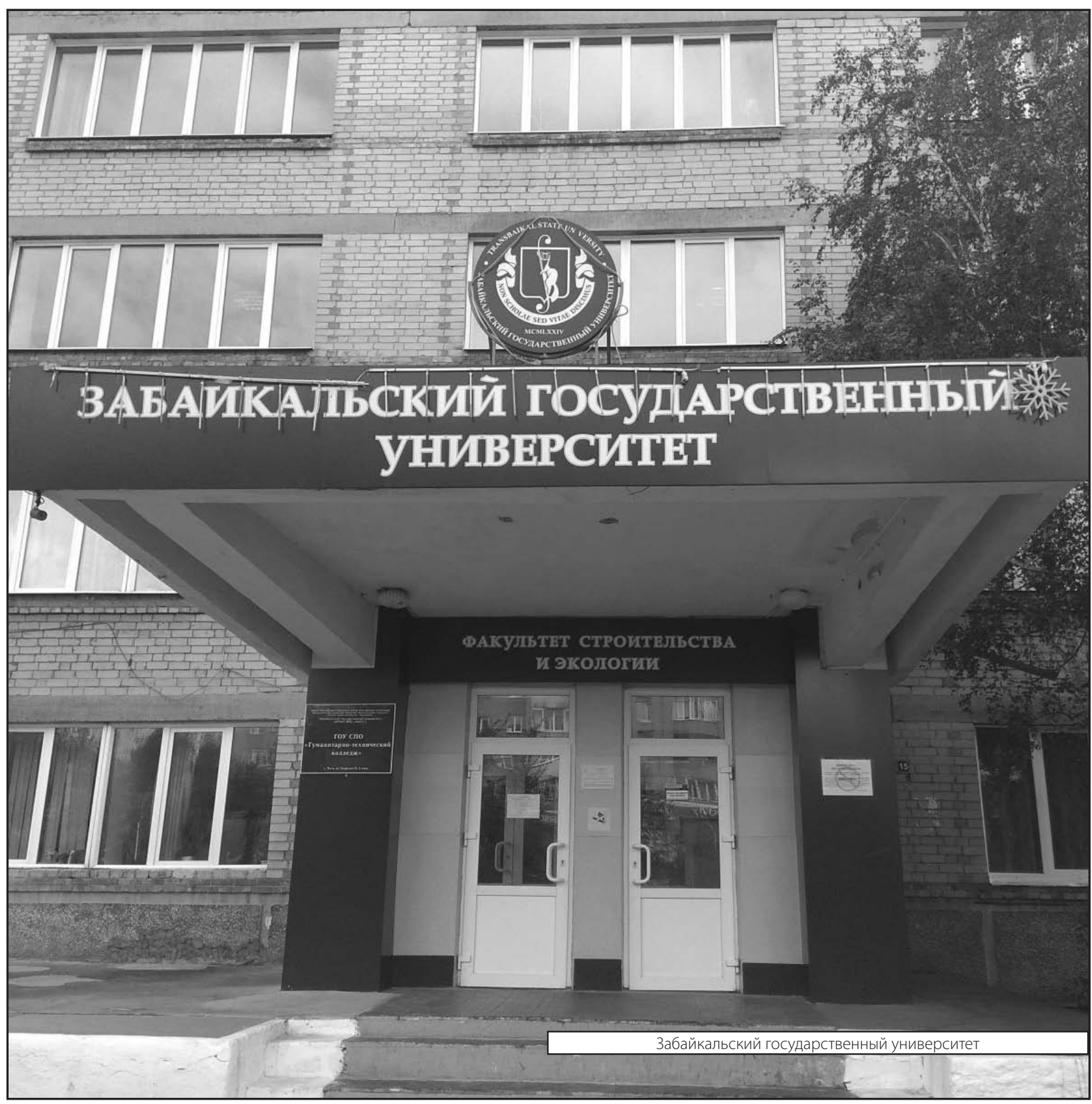